\title{
Origination and Transmission of Impulse in the Right Auricle
}

\author{
Kazuo Yamada, M.D., * Maretsugu Horiba, M.D., ** Yukio \\ Sakaida, Ph. D., * Mitsuharu OKajima, M.D., * Hiroshi \\ Horibe, M.D., * Hiroshige Murakr, M.D., * \\ Toshiji Kobayashi, M.D., * Atsuyoshi \\ Miyauchi, M.D., ${ }^{* *}$ Hiroshi Oishi, M.D., ** Akira \\ Nonogawa, M.D., ** Kazuo Ishikawa, M.D., ** \\ and Junji Toyama, M.D.**
}

TN 1907, Keith \& Flack" found the sino-atrial node (S-A node) in the right atrial musculature at the boundary to the vena cava superior, and in 1906, Tawara ${ }^{2}$ found the atrio-ventricular node (A-V node) in the septal musculature of the right atrium near the atrio-ventricular ring (A-V ring). Thereafter, many researches have been made on the stimulus conduction in the right atrial musculature.

The fact that the impulse as the cardiac pacemaker initiates at the S-A node had been originally established by Wybaw, ${ }^{3)}$ Lewis, ${ }^{4)}$ Eyster ${ }^{5)}$ and others and it is beyond controversy even with the findings obtained by modern expcrimental tcchniques.

However, as to the mechanism of impulse initiation and the route by which the impulse travels from the S-A node to the A-V node, a number of papers have been published without resulting in universal agreement of opinions.

Some investigators, including Koch, ${ }^{6)}$ Rothberger and Scherf, ${ }^{71}$ Condorelli, ${ }^{8)}$ Takayasu ${ }^{9)}$ and others, proposed a specialized conducting system, through which the impulse originated in the S-A node was transmitted to the $A-V$ node, whereas others, including Lewis ${ }^{10)}$ and Puech, ${ }^{11)}$ denied the existence of this system.

Most of the experimental studies of the investigators mentioned above were performed by means of direct lead method of electrocardiogram using various type of needle electrodes. Recently, the advent of the technique of microelectrode ${ }^{12), 13)}$ has made it possible to record the transmembrane potential change of each cell of the muscle fibers. According to the report ${ }^{14)}$ on the

\footnotetext{
* From the Research Institute of Environmental Medicine, Nagoya University. Director: Prof. Hideo Toyoshima, M.D.

** From the First Department of Internal Medicine, Nagoya University. Director : Prof. Susumu Hibino, M.D.
} 
transmembrane potential, the transmembrane potential of each cell is specific to the kind of cell in its pattern. Thus, it makes us possible to identify the kind of cells and to obtain a critical information on the activation time of the cell concerned.

In our laboratory, a series of experimental studies on impulse propagation in the atrial musculature have been made by means of microelectrode method since 1958, and comprehensive report will be presented in this paper, including a fraction reported before elsewhere in this Journal ${ }^{15)-18}$ ) and others. ${ }^{19), 20)}$

\section{Method}

Thirty-six adult mongrel dogs weighing 5 to $10 \mathrm{Kg}$. and 31 adult rabbits weighing 2.0 to $2.9 \mathrm{Kg}$. were used. The animals were anesthetized by the intravenous or the intraperitoneal administration of 40 to $80 \mathrm{mg}$. of methylhexabital natrium per $\mathrm{Kg}$. of the body weight.

The chest was then opened and the heart was removed as quickly as possible into a receptacle filled with oxygenated Tyrode's solution kept at a constant temperature level of 32 to $34^{\circ} \mathrm{C}$. Both the right and left ventricles and the left atrium were cut off at a line near the boundary to the right atrium (about $0.5 \mathrm{~cm}$. to the boundary).

The right atrium was then opened by making a cut through the anterior atrial free wall along the atrial septum up to the vena cava superior. Thus a large specimen of the right atrium was prepared. The septal branch of the crista terminalis of the specimen thus prepared is cut off between the septum and sinus node. The preparation was sometimes made in a different way, that is, first a cut was made through the anterior free wall along the atrial septum up to the basement of the auricular appendage near aorta, then a cut was made from there toward the apex of the auricular appendage up to the apex. Thus the inner surface of the right atrium was exposed without making a cut through the crista terminalis. The latter specimen was offered to the study of impulse conduction in the right atrial musculature.

The specimen was spread on a paraffin block and was pinned on it. In this case, the endocardial surface faced out away from the paraffin block. The entire specimen was immersed into Tyrode's solution prepared in a thermostatic bath. The specimen was constantly irrigated in the bath $(20$ to $30 \mathrm{ml} . / \mathrm{min}$.) with isothermic Tyrode's solution. The composition of the solution was as follows: NaCl: 137 mmol, $\mathrm{NaHCO}_{3}: 4.8 \mathrm{mmol}$, Dextrose : $5.5 \mathrm{mmol}, \mathrm{CaCl}_{2}: 1.9 \mathrm{mmol}, \mathrm{KCl}: 2.7 \mathrm{mmol}$, $\mathrm{MgCl}_{2}: 0.5 \mathrm{mmol}$, and $\mathrm{NaH}_{2} \mathrm{PO}_{4}: 3.6 \mathrm{mmol}$. $\mathrm{pH}$ was calibrated to 7.2 at the solution temperature of $32^{\circ} \mathrm{C}$.

The penetration by a microelectrode was performed through the endocardial surface. Experiments were performed under spontaneous regular sinus rhythm or under artificial driving. A capillary glass tube electrode was used for the intracellular potential recording, the tip of the microelectrode being less than $0.5 \mu$. in diameter. The microelectrode was filled with $3 \mathrm{~mol} \mathrm{KCl}$ and its electrical resistance 
ranged from 10 to $20 \mathrm{M} \Omega$.

As a time reference, a unipolar lead electrogram was simultaneously recorded from an atrial point near the boundary to the anterior part of superior vena cava. The indifferent electrodes for both intracellular and surface lead electrograms were located at 2 different points in the Tyrode's solution keeping a distance as far as possible from the specimen. Electrode for artificial driving was made of AgCl coated silver wire. The wire was insulated by covering glass tubing except the tip of it.

The stimulus for artificial driving was given by unipolar or bipolar electrode. The electrode distance in bipolar stimulation was less than $1.5 \mathrm{~mm}$. The electrode for stimulation was placed at a point of the endocardial area suspected to cover the sinus node region. The frequency of the stimulation was 60 to 90 cycles per min. for the driving of canine heart and about 110 to 130 cycles per min. for the driving of rabbit heart. The stimulus current was rectangular in its shape. The duration of stimulus was constantly $2 \mathrm{msec}$. and the voltage of it was 3 to 4 volts. The intracellular electrogram was checked point by point moving the microelectrode along the endocardial surface. The movement of the microelectrode was made with the aid of micromanipulator. The distance moved was measured through the use of vernier attached to the manipulator.

The preamplifier used for the intracellular potential recording was type MZ-IB made by Nihonkoden Kogyo Co., and that for the surface electrogram was type ADB-1 made by the same company. The output voltage from these preamplifiers were introduced to a 2 beam cathode ray oscilloscope made by the same company. The movement of the spot on the screen glass was photographed at a constant film speed of 5 or $10 \mathrm{~cm}$. per sec. with the aid of a continuous recording camera made by Saneisokki Co.

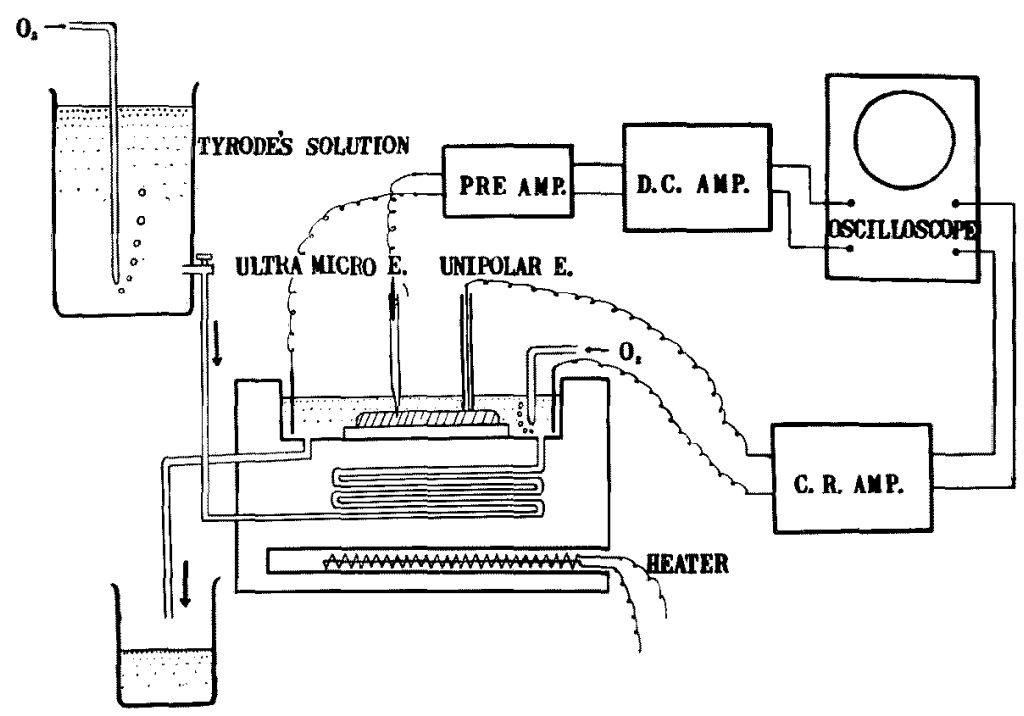

Fig. 1. Diagramatical illustration of the experimental technique. 


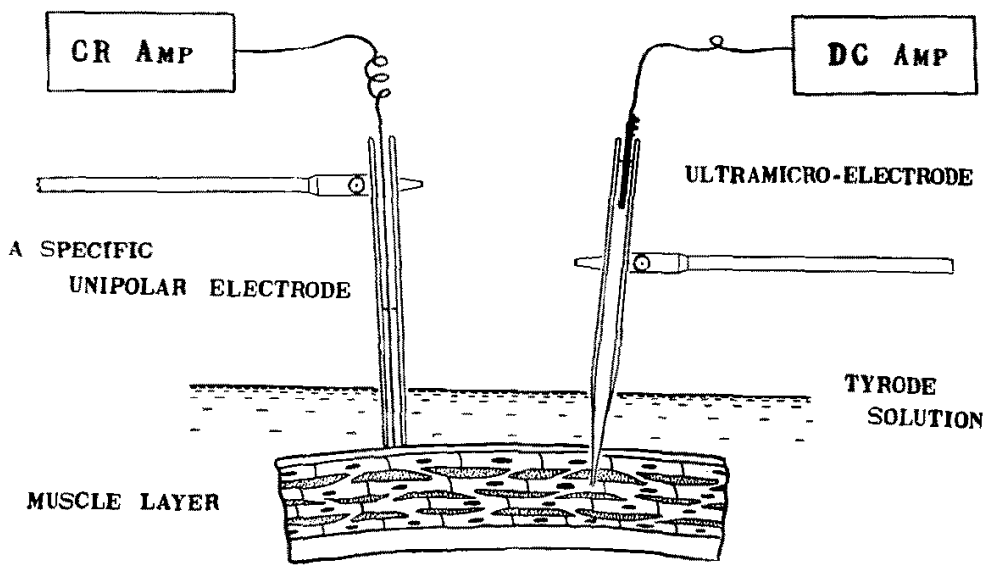

Fig. 2. Arrangement of an ultramicroelectrode and a simultaneous unipolar electrode.

For the discussion of the arrival time of activation wave, the onset of the sharp depolarization upstroke of the membrane action potential was used as a remark of the onset of activation at the cell penetrated. The arrival time of activation wave was, therefore, given by the time interval from the onset of the intrinsic deflection of the unipolar lead electrogram in the reference lead to the onset of the sharp depolarization upstroke of the intracellular electrogram of the cell penetrated. In the case of artificial driving, the time interval from the onset of escaped current to the onset of the sharp depolarization upstroke of the intracellular electrogram was measured to compare the arrival time of activation wave. Outline of the experimental apparatus was schematically illustrated in Figs. 1 and 2.

For the convenience to describe the experimental results in this paper, crista terminalis was divided into 2 parts separated at a point near the S-A node. The one termed as the right branch. This branch was the part running along the atrial free wall. The other was termed as the septal branch. This branch was a part extending into the atrial septum. There was no essential difference in the manner of stimulus conduction between the 2 species of animal as well as between the the sinus rhythm and the artificial driving.

\section{RESULT}

1) S-A node and its vicinity

Experiments were performed on 9 rabbits under the natural sinus rhythm. Fig. 3 demonstrates the frontal view of the right atrial inside. As shown in Fig. 3, the cells showing diastolic slow depolarization in their membrane action potentials were located distributing in a lozenge shaped area as encircled by a dotted line. The length of each side of the lozenge was about $4 \mathrm{~mm}$. This area was located in the atrial tissue between the 2 caval orifices and included a part of the right branch of the crista terminalis. This area 
mainly occupied the right anterior area of the basic wall of the superior vena cava. The area was nearly the same in its location and size with the S-A node area histologically demonstrated by many authors.

The configurations of the intracellular electrograms recorded from this S-A nodal region were roughly classified into 2 different types. One was the type characterized by increased rate of the diastolic slow depolarization, gentle depolarization upstroke, and by gradual transition of the trace from the diastolic slow depolarization to the gentle depolarization upstroke of the membrane action potential. The amplitude of both the membrane resting and

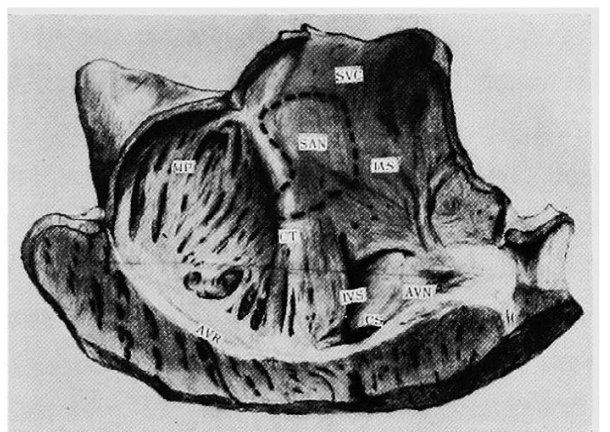

Fig. 3. Frontal view of the endocardial surface of right atrium. The dotted line encloses the area where the diastolic slow depolarization in the transmembrane potential was recorded. The superior vena cava was cut open in this figure.

SVC: Superior vena cava. CT: Crista terminalis.

MP : Musculi pectinati, AVR: Atrioventricular ring.

SAN : Sino-atrial node. AVN: Atrioventricular node.

IAS : Interatrial septum. IVS: Inferior vena cava.

CS : Coronary sinus orifice.

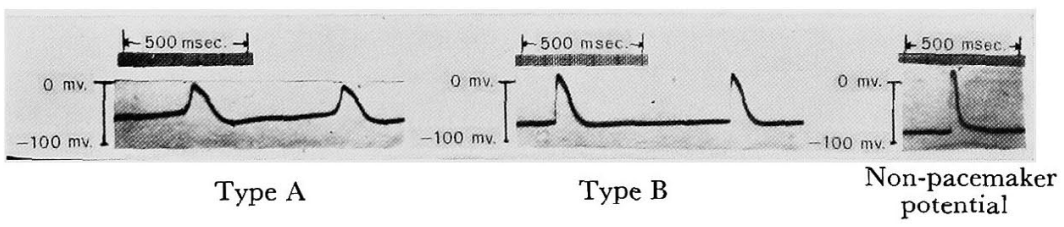

Fig. 4. Patterns of 2 different kinds of pacemaker potential and of a nonpacemaker potential.

Type A is characterized by a moderately sloped diastolic slow depolarization preceding a gentle upstroke of the action potential and decreased membrane resting and action potentials.

Type B is characterized by a very slightly sloped diastolic slow depolarization, a sharp upstroke of the action potential, and by an increased membrane resting and action potentials.

The extreme right record shows the non-pacemaker potential from the adjoining area of the pacemaker region. This pattern is characterized by the absence of a slow diastolic depolarization, by sharp upstroke of the action potential, and by larger membrane resting and action potentials than those found in Type B. 
action potentials were small and the depolarization upstroke was lacked in overshoot or very minor even if it occurs. This type was referred to as Type A. The other was the type characterized by a very minor rate of the diastolic slow depolarization, sharp depolarization upstroke, and by abrupt transition of the trace from the diastolic slow depolarization to the sharp depolarization upstroke of the membrane action potential. The amplitude of both the membrane resting and action potentials were large compared with Type $\mathrm{A}$ and there was always appreciable amount of overshoot. This type was referred to as Type B (Fig. 4).

Type A was obtained from the densely dotted area of the S-A nodal region as shown in Fig. 5, and Type $\mathrm{B}$, from the sparsely dotted area around the former. The area showing Type A was located in a slender area near the crista terminalis ( 1 to $1.5 \mathrm{~mm}$. from it) lying down along it. The right end of this Type A area extended into crista terminalis near the right upper part of the orifice of the inferior vena cava as shown in Fig. 5. The entire length of those area was measured about $4 \mathrm{~mm}$.

The statistical means of the membrane resting and action potentials of Type A transmembrane potential were $58 \pm 8 \mathrm{mv}$. and $56 \pm 8 \mathrm{mv}$. respectively, and those of Type B potential, $70 \pm 12 \mathrm{mv}$. and $81 \pm 14 \mathrm{mv}$. respectively (Values were given by the mean \pm standard deviation). The depolarization velocity of the diastolic slow depolarization and the firing threshold were $35 \pm 7 \mathrm{mv}$. $/ \mathrm{sec}$. and $45 \pm 11 \mathrm{mv}$. respectively in Type A potential and $20 \pm 14 \mathrm{mv}$. /sec. and

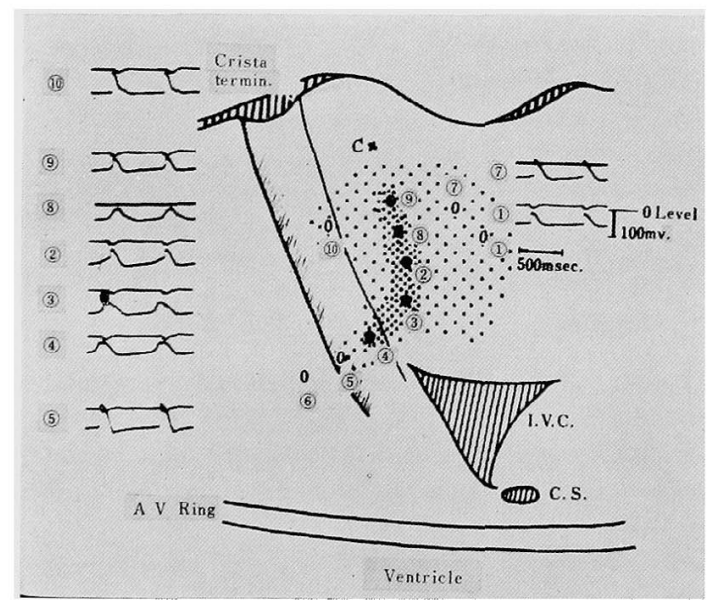

Fig. 5. Two different types of the pacemaker potential in S-A node region in the right atrium of a rabbit. Type A potential was obtained from the densely dotted area, and Type B potential, from the sparsely dotted area. The earliest onset of the pacemaker potential was found at point 3 .

The unipolar lead electrogram was recorded from point G. 
$63 \pm 14$ mv. respectively in Type B potential.

In order to find the true pacemaker, many points of the S-A nodal region were explored and the onsets of the sharp depolarization upstrokes of the membrane action potentials from these points were compared. The point earliest in the onset of activation was located almost always in a small localized area of the S-A node around point 3 in Fig. 5.

Fig. 6 demonstrates the onset of the membrane action potential from 6 points around the true pacemaker (Fig. 5) as compared with the time reference. Points 2, 3 and 4 exhibit Type A, 1 and 5 exhibit Type B, and 6 exhibits non-pacemaker pattern of potential. As may be seen in Fig. 6, the onset of the membrane action potential is the earliest at point 3. The location of this true pacemaker was observed to be in the basal part of the right wall of superior vena cava.

By comparing the onsets of the membrane action potentials from various points of S-A node, it was found that the activation evoked in the pacemaker was conducted almost radially in directions. The conduction rate of the activation in general was observed to be late (about 0.01 to $0.02 \mathrm{M}$. $/ \mathrm{sec}$ ). In only one direction from point 3 on the true pacemaker to point 4 on the crista terminalis, the activation was transmitted rapidly (about $0.08 \mathrm{M}$./sec.).

2) Conduction of activation in right atrial musculature

Animals offered to the experiment were 20 adult mongrel dogs and 8 adult rabbits. From the order of onset of the sharp depolarization upstroke

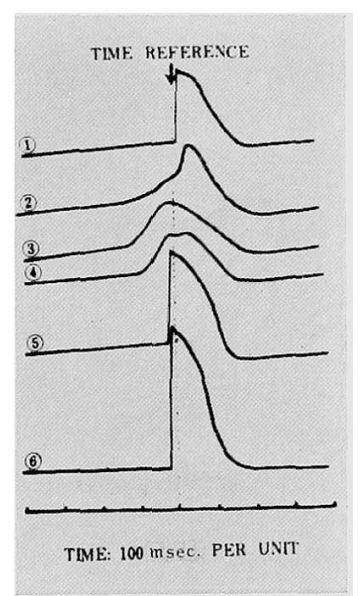

Fig. 6. The time relationship between the onset of the action potential at various points in the right atrium. Each tracing numbered from 1 to 6 is the action potential from the correspondingly numbered points in Fig. 5.

The dotted vertical line is the time reference and indicates the onset of the intrinsic deflection of a simultaneous unipolar lead electrogram. 


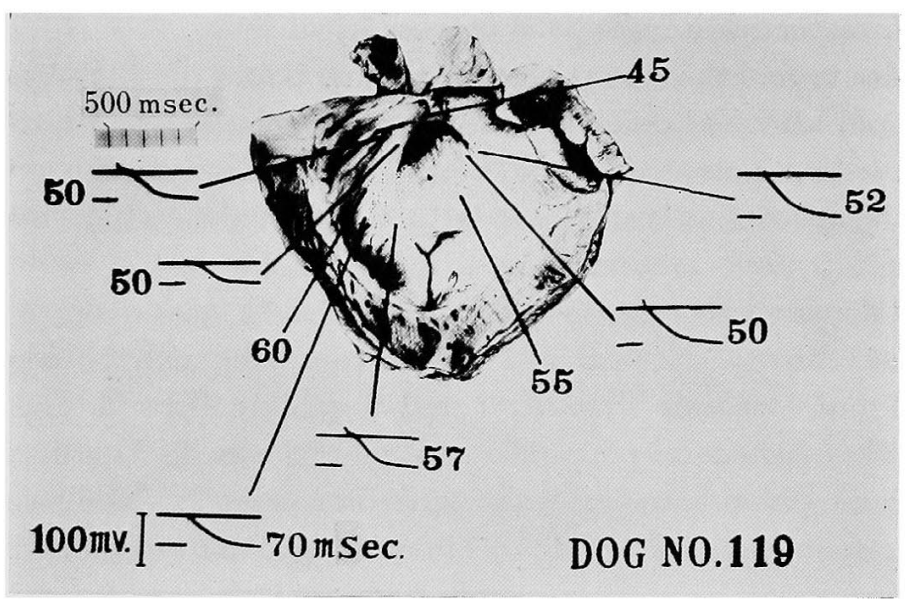

Fig. 7. Configurations and activation times of membrane action potentials at various points along crista terminalis under artificial driving of S-A nodal region. In each trace, the upper indicates the zero potential level, and the bottom, intracellular action potential. Each numeral indicates activation time in msec. from artifact of driving.

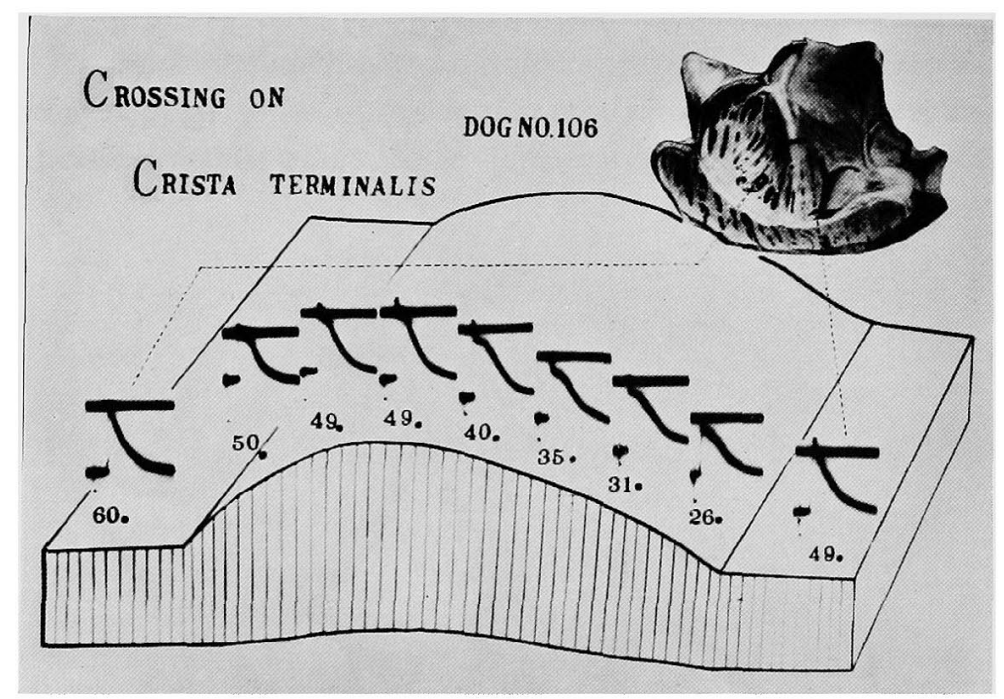

Fig. 8. Configurations and activation times of membrane action potentials from serial points across crista terminalis under artificial driving. Numerals inserted express activation times in msec.

of the membrane action potentials recorded from various points of the right atrial endocardium, it was observed that the activation which had arrived at crista terminalis from the pacemaker propagated with increased velocity along 
the right and septal branches of the crista terminalis (Fig. 7). The velocity was about $1.5 \mathrm{M}$./sec. and was much higher than that in sinus node. According to the observations explored across the crista terminalis, the onset of the activation was earlier at the inner side of the crista terminalis than at the outer side (Fig. 8).

The atrial septum and free wall was observed to be activated by the impulse coming along through crista terminalis.

Characteristics of the membrane action potential recorded from the crista terminalis was as follows. The resting potential was the greatest of all the atrial musculatures, and the transition of the trace to the depolarization upstroke was very sharp. The depolarization upstroke was also the sharpest of all the atrial musculatures. The spike was very sharp and the overshoot was quite marked. There was a discernible plateau, even though it was not so remarkable as in the membrane action potential of the ventricular muscle fiber.

As may be seen in Figs. 7 and 9, the activation originated in S-A node was preferentially conducted through the both branches of crista terminalis, and then it was farther transmitted into $\mathrm{mm}$. pectinati via these branches of crista terminalis. The conduction velocity of the activation through $\mathrm{mm}$. pectinati was about 0.6 to $1.0 \mathrm{M}$./sec. The value was less than that through

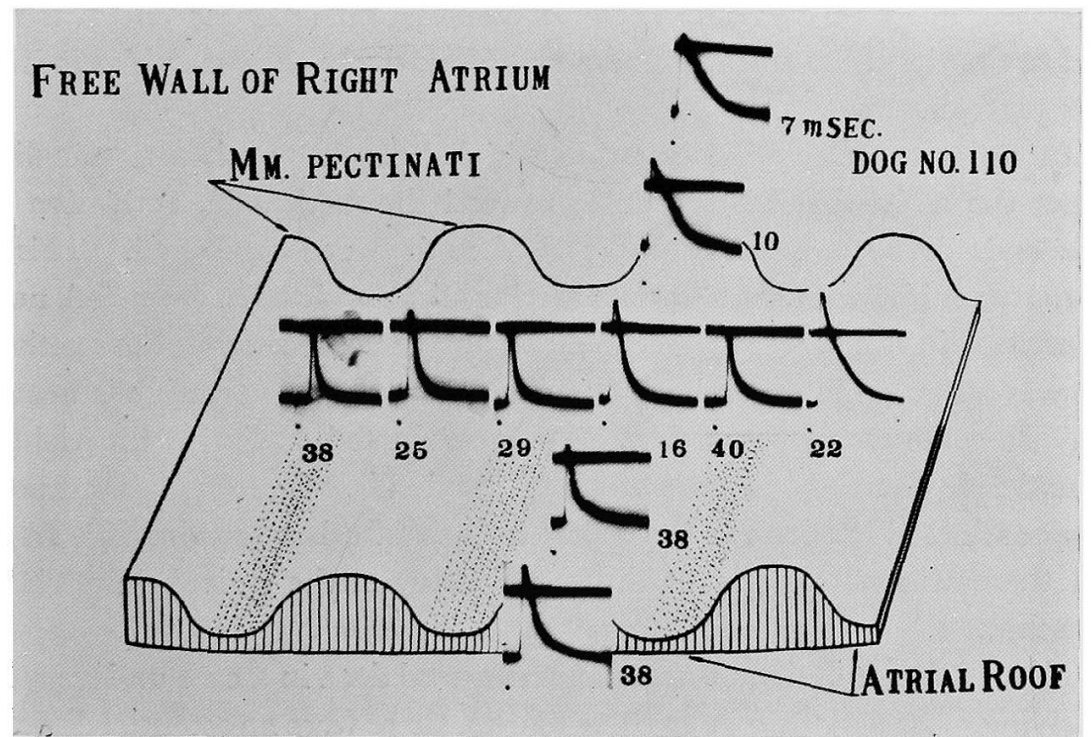

Fig. 9. Configurations and activation times of membrane action potentials from serial points along a canine $m$. pectinatus and atrial roof under artificial driving of S-A nodal region.

Significant difference in configuration of action potentials is seen between $\mathrm{mm}$. pectinati and atrial roof. Numerals inserted express activation in msec. 
crista terminalis but was greater than that though the atrial roof musculature. The atrial roof musculatures on both sides of $m$. pectinatus were always activated later than the ridge of a $\mathrm{m}$. pectinatus locating at the same level. This appeared to suggest that the activation of the atrial roof musculature was evoked by the stimulus coming along through $\mathrm{mm}$. pectinati. The conduction rate in the atrial roof musculature was about 0.4 to $0.8 \mathrm{M}$. $/ \mathrm{sec}$.

The shape of the membrane action potential of the atrial roof musculature was different from that of $\mathrm{m}$. pectinatus. That is, the action membrane potential of the atrial roof muscle displayed no plateau while that of $\mathrm{m}$. pectinatus discernible but very minor plateau. As it is well known, most of $\mathrm{mm}$. pectinati run from crista terminalis toward the $A-V$ ring. The propagation of the activation was also observed to be in the same directions as the runs of ridges of $\mathrm{mm}$. pectinati.

In the area of the right surface of the atrial septum, activation was observed to be propagated through the septal branch of the crista terminalis. The activation of the septal branch of crista terminalis was farther transmitted to the anterior, posterior and inferior part of septum.

The configuration of the membrane action potential from this branch of crista terminalis was the same as that explained with right branch. The membrane action potential from the septal area except crista terminalis was rather slow in its initial part of the depolarization upstroke and was rather round at the tip of the spike. There was a relatively clear shoulder indicative of the plateau.

In order to clarify the question which branch of crista terminalis can conduct the activation more quickly toward the A-V node, activation times at the ends of both branches near A-V node were compared. This may be a matter of importance to discuss the impulse conduction from S-A node to $\mathrm{A}-\mathrm{V}$ node. In the present experiment, no critical difference of the activation times was observed between both terminal areas of crista terminalis near $\mathrm{A}-\mathrm{V}$ node. In some cases, the activation was conducted earlier to the vicinity of A-V node via the right branch of crista terminalis. In some cases, however, it was conducted earlier via the septal branch of crista terminalis. In other cases, there was no significant difference between the arrival times via these 2 branches.

Figs. $10 \mathrm{~A}$ and $\mathrm{B}$ demonstrate experimental data in a case under an artificial driving. As may be seen in these figures, there were no essential differences in the auricular activation process or in the configurations of the transmembrane potential between the 2 different conditions of artificial driving and natural sinus rhythm. 


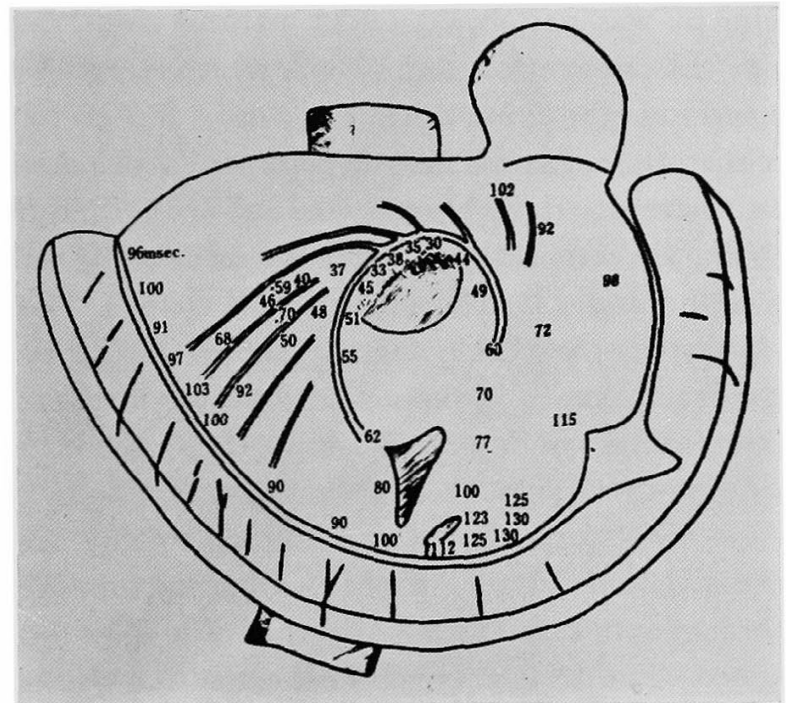

Fig. 10 (A). Activation times of membrane action potentials from various points covering the whole area of the endocardial surface of canine right atrium.

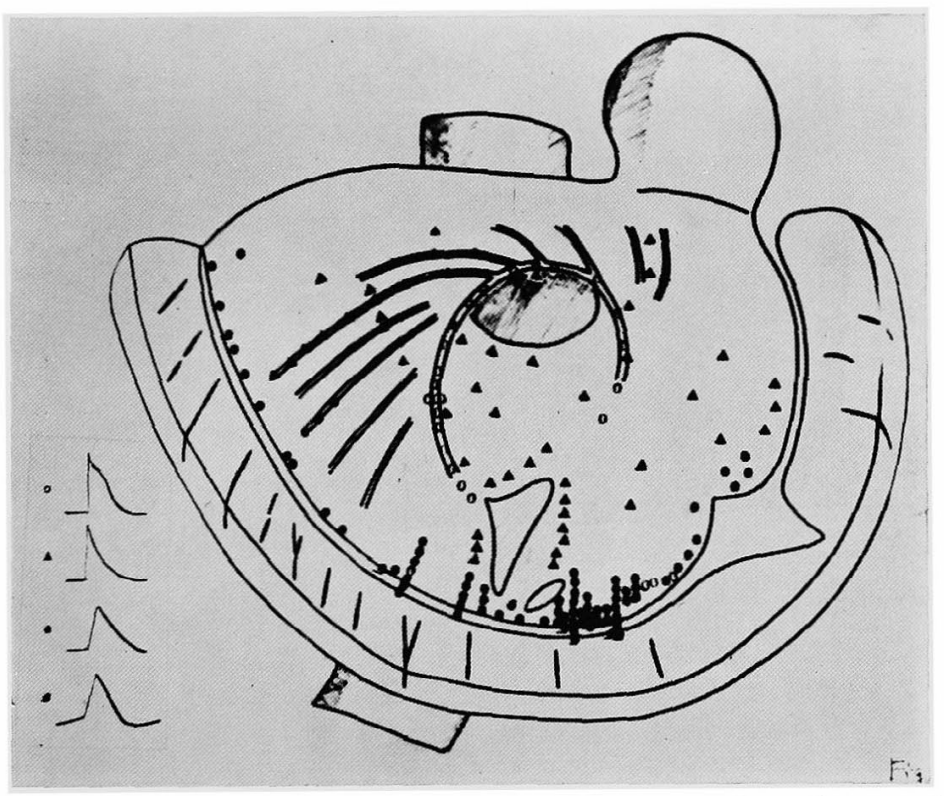

Fig. 10 (B). Distribution of 4 representative patterns of membrane action potentials from the canine right atrium under artificial stimulation of S-A nodal region.

\section{Cutting of the crista terminalis}

Animals offered to the experiments were 8 adult dogs and 2 adult 
rabbits. Experiment was performed under natural sinus rhythm or under artificial driving. Electrodes for unipolar lead electrogram and artificial driving were placed on the crista terminalis near the center of S-A node. Cutting of the crista terminalis was made through the use of a sharp small scissors.

In the case where the right branch was cut at the middle of its course, (point B in Fig. 11), the activation times measured at many points of the area proximal to the cut point did not show appreciable change. In the distal area, however, they displayed remarkable delay as shown in Fig. 11. In this case, there was no significant change in the activation time in the septal area. In the case where the farther cut was made across the septal branch (point $\mathrm{G}$ in this figure) in addition to the right branch, the activation times at various points of the distal area of the septum displayed remarkable delay, while those of the proximal area displayed no delay. The activation time in the distal area after section of both branches of crista terminalis was 1.7 to 2.8 times later as much as the normal value. The delay in onset of the activation was more remarkable

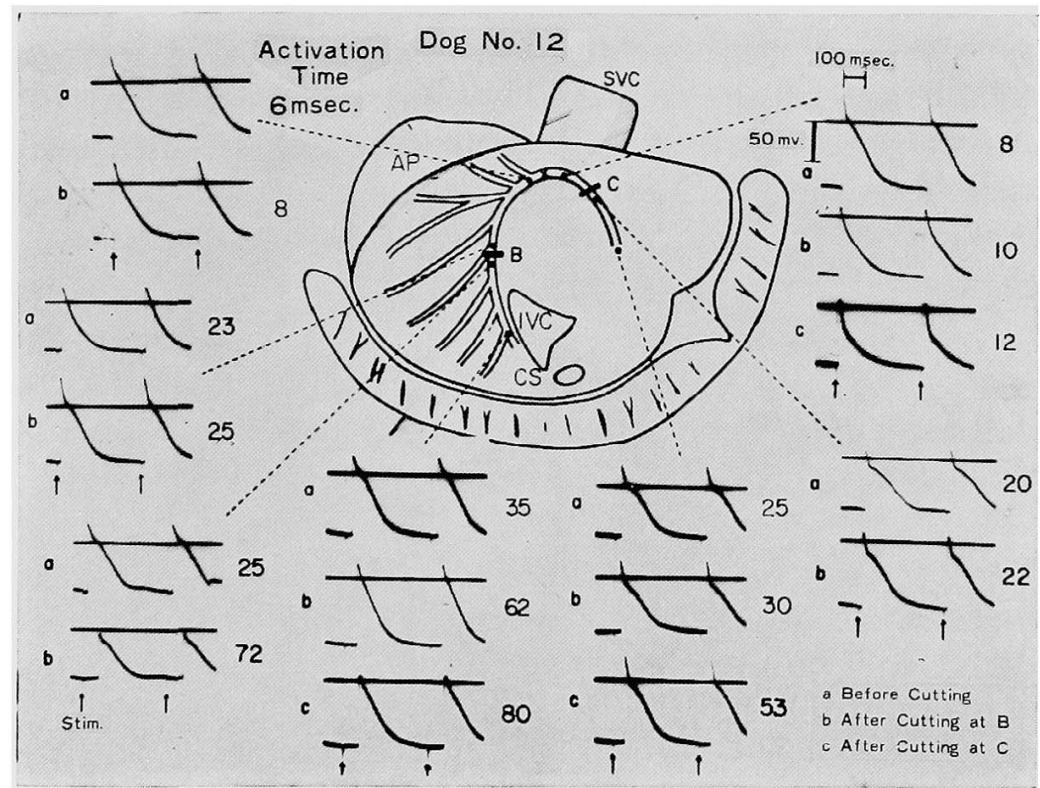

Fig. 11. Configurations and activation times of membrane action potentials at various points of crista terminalis before and after cutting crista terminalis. The specimen is contracting by artificial stimulation driven at point $X$. Among those tracings, the tracings (a) represent the membrane action potential before cutting, and the tracings (b), those after cutting wihch was made across the crista terminalis at point $B$ on the right branch of this tissue. The tracings (c) represent the membrane action potentials after additional cutting made at point $\mathbf{C}$ of the septal branch. Numerals inserted express activation times in msec. In the area distal to the cut point, activation times displayed remarkable delay after making a cut across the crista terminalis. 
in the distal area near the cut point as compared with control.

Fig. 12 demonstrates the activation times at various points of $\mathrm{mm}$. pectinati of atrial free wall in control and after making a cut through the right branch of crista terminalis. The activation times at various points of $\mathrm{mm}$. pectinati branched from the proximal part of crista terminalis displayed no remarkable changes in their value, while those of $\mathrm{mm}$. pectinati branched from the distal part displayed remarkable delay. Minor change in the location of the microelectrode may account for the minor change of activation time in the proximal area but not for the great change in the distal area.

In the case where the cut was made first across the right branch of crista terminalis and then across the septal branch, the activation time in the vicinity of A-V node displayed some minor change by the first cut and greater change by the second cut (Fig. 13).

Even though the first cut was made across the septal branch and the second cut was made across the right branch, the activation times in the vicinity of $\mathrm{A}-\mathrm{V}$ node did not show any great change by the first cut, whereas they displayed marked delay by the second cut. There was no appreciable

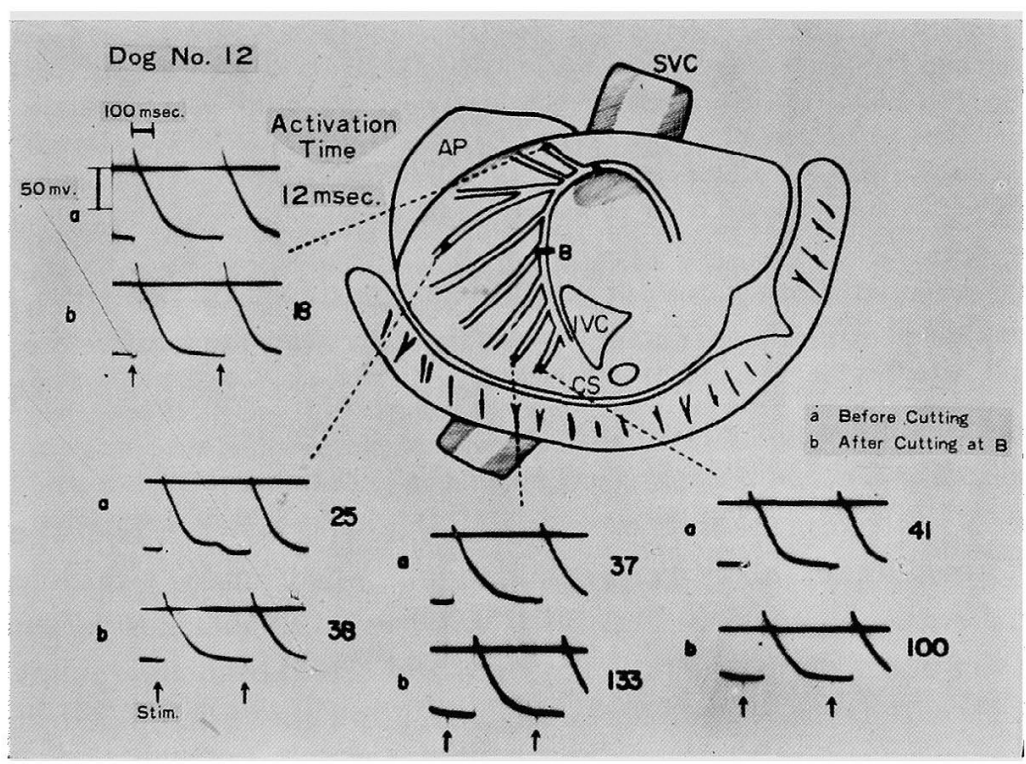

Fig. 12. Configurations and activation times of membrane action potentials at various points of $\mathrm{mm}$. pectinati before and after cutting crista terminalis. The specimen is contracting by artificial driving at point $\mathrm{X}$. The tracings (a) represent the membrane action potentials before cutting, and tracings (b), those after cutting the right branch of crista terminalis at point $B$. The activation times at various points of $\mathrm{mm}$. pectinati branched from the distal part of crista terminalis showed marked delay in their value. 


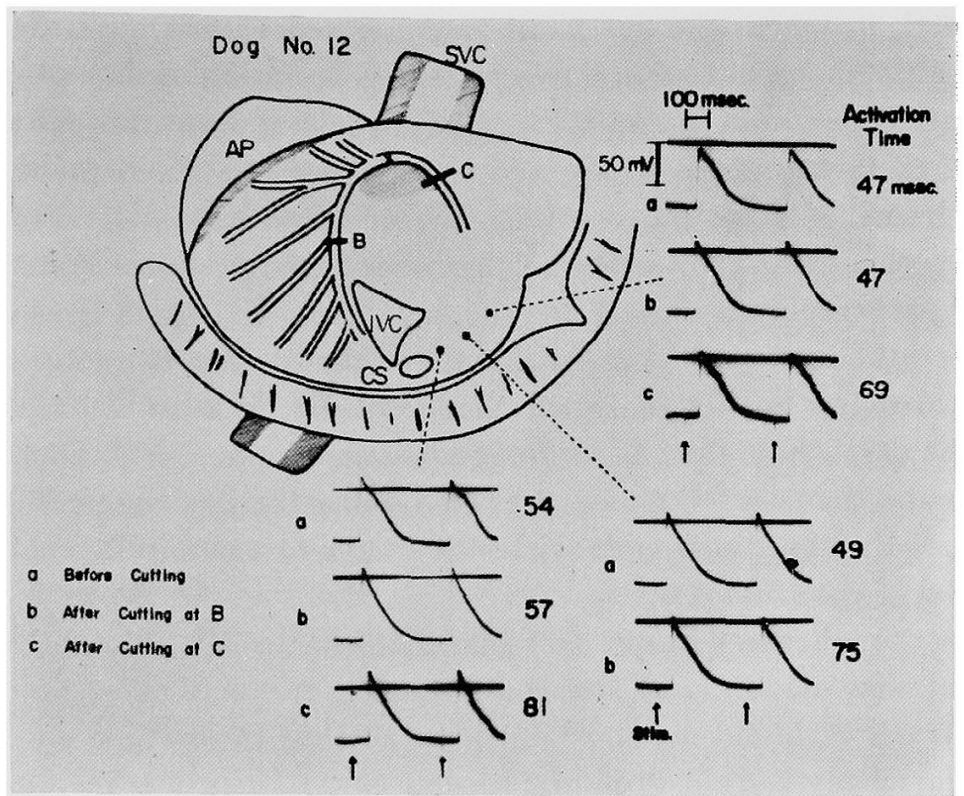

Fig. 13. Configurations and activation times of membrane action potentials from the vicinity of A-V node region before and after cutting crista terminalis. The specimen is contracting under artificial stimulation driven at point X. Among those tracings, tracings (a) represent the membrane action potentials before cutting, tracings (b), those after cutting made at point $\mathrm{B}$ of the right branch of crista terminalis, and tracings (c), those after additional cutting made at point $\mathrm{C}$ of the septal branch. Activation times in this area did not show any marked delay by first cut (at point B), whereas, showed marked delay by second cut (at point $\mathrm{G}$ ).

difference between both values of minor delay produced by first cut. It was, therefore, very difficult to decide which branch was more effective to the delay in onset of activation time at this area. Farther experiments should be made for the discussion of this problem.

Osmic acid injection into the cirsta terminalis

Twenty-one adult rabbits were used in this experiment. The experiment was performed under the artificial stimulation. The stimulus was given to the S-A nodal region (X mark in Fig. 14). 0.009 to $0.011 \mathrm{ml}$. of $2 \%$ osmic acid solution was injected into the ridges of right and septal branches (points $\mathrm{R}$ and $\mathrm{S}$ in Fig. 14) of the crista terminalis through the use of glass micropipette injector.

The arrival times of activation to the both branches of the crista terminalis distal to the injection points were measured before and after osmic acid administration. The arrival time of activation wave to the area in the vicinity of the $\mathrm{A}-\mathrm{V}$ node was also measured.

The injection was at first performed into the right branch $(R)$ of the crista terminalis. As may be seen in the second row of Fig. 14, the arrival 


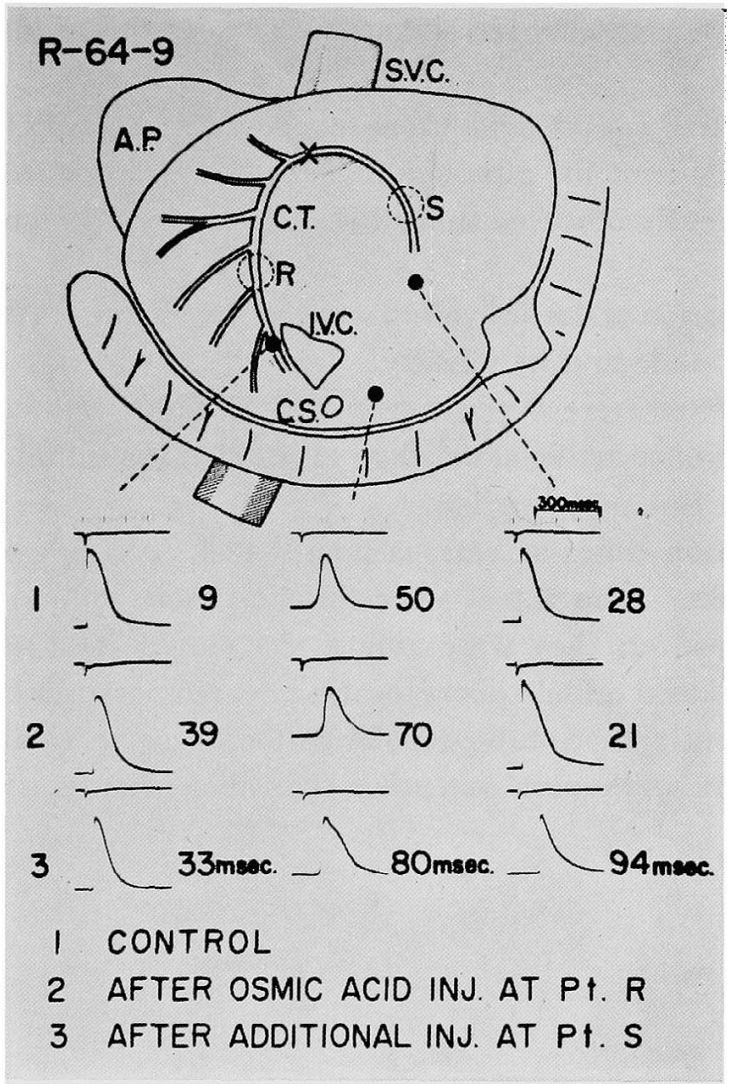

Fig. 14. Configuration and activation times at the various points on peripheral portion of both branches of crista terminalis and the point in A-V nodal region. The records were obtained before and after injection of osmic acid solution into the crista terminalis. Among those tracings, tracing (1) represents the membrane action potentials before the injection, tracing (2), those after the injection performed into point $\mathrm{R}$ of the right branch, and tracing (3), those after additional injection made into point $S$ of the septal branch. The activation time at the right branch showed marked change by first injection (point $R$ ), whereas at the A-V nodal region, moderate delay was observed and at the septal branch, no remarkable delay was observed. After additional injection made at point $\mathrm{S}$, the activation time at the right branch did not show any marked delay, whereas at the A-V nodal region showed additional delay, and at the septal branch showed marked delay.

times of the activation to the caudal portions of the right branch and to the area in the vicinity of the A-V node displayed marked delay, while there was no discernible change observed in the arrival time to the distal area of the septal branch. The additional injection of the same solution was then performed into the septal branch (S). As may be seen in the third row of this figure, the arrival time to the caudal portion of the septal branch displayed marked delay and that to the area in the vicinity of the $\mathrm{A}-\mathrm{V}$ node showed further delay, while therc 
was no more change observed in the arrival time to the caudal portion of the right branch.

The intra-atrial complete block, as reported by Tamai, ${ }^{21)}$ was not observed in the present experiment, although the tachycardia and a few arrhythmic beats were transiently observed immediately after the injections of osmic acid solution.

3) Propagation of the activation wave in the vicinity of the A-V ring and in $\mathrm{A}-\mathrm{V}$ node and its vicinity.

Animals offered were 8 adult dogs and 12 adult rabbits. Experiments were performed under artificial driving. Electrode for stimulation was placed at a point of the S-A nodal region.

The activation times at various points near $\mathrm{A}-\mathrm{V}$ ring were in a range of 70 to $100 \mathrm{msec}$. The values were different from animal to animal. In each animal, however, they were almost the same. The membrane action potentials of the atrial muscle fibers locating near A-V ring were characterized by a relatively gentle slope of the depolarization upstroke, smaller amplitude of membrane resting and action potentials than that of ordinary atrial free wall

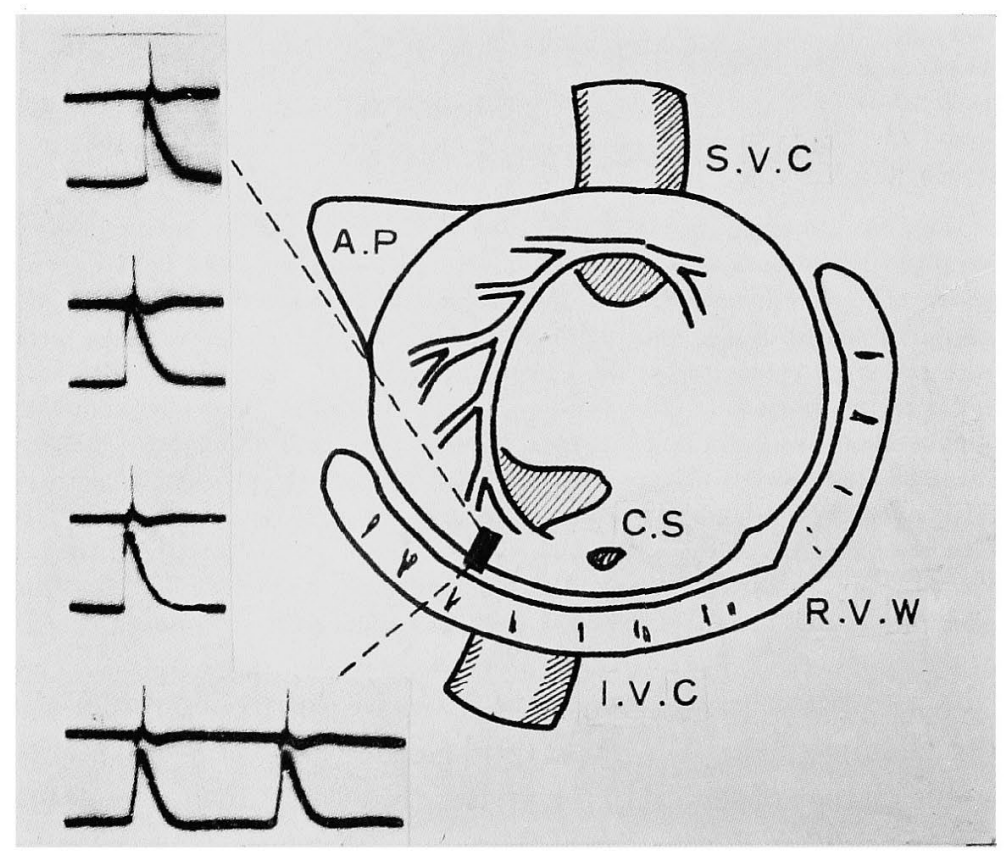

Fig. 15. Configurations of membrane action potentials from the points along a line vertical to $\mathrm{A}-\mathrm{V}$ ring. The line was located $10 \mathrm{~mm}$. posterior to the coronary sinus orifice. A series of recording is made at intervals of $1 \mathrm{~mm}$. The tracing from the point nearest to $\mathrm{A}-\mathrm{V}$ ring shows a diastolic slow depolarization. 


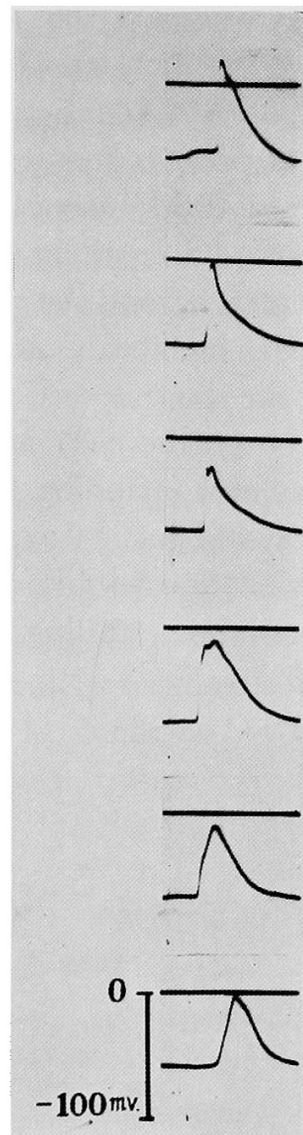

$$
\begin{gathered}
\text { Activation } \\
\text { time in msec. }
\end{gathered}
$$

Fig. 16. Configurations, activation times and durations of rising phases of membrane action potentials recorded from points along a line vertical to A-V ring. The line was located about $8 \mathrm{~mm}$. posterior to the coronary sinus orifice. A series of recording are made at intervals of $1 \mathrm{~mm}$. As the $\mathrm{A}-\mathrm{V}$ ring is approached (from the top to the bottom in this figure), the activation time and the durations of rising phase progressively increased and the amplitude tended to decrease.

musculature, and by decreased or lacked overshoot. Usually the diastolic slow depolarization was not found in this area. In some cases, however, there was a small circumscribed area displaying diastolic prepotential. Fig. 15 demonstrates a case in which the diastolic prepotential was found at a small area near the ring. This area was located about $10 \mathrm{~mm}$. right anterior to the coronary sinus orifice of rabbit heart.

Fig. 16 demonstrates an example of the data in vertical exploration toward the A-V ring. The exploration was made near the orifice of coronary sinus of canine heart (about $8 \mathrm{~mm}$. posterior to the orifice). As the electrode approached the A-V ring, the slope of the depolarization upstroke became pro- 
gressively less steep and onset of the depolarization upstroke or activation time became progressively delayed. The same observation was also found at different area along the ring.

The change in the steepness of the depolarization upstroke was more marked than the delay in the activation time. With increasing changes of the steepness and activation time, there was gradual decrease in membrane resting and action potentials. In the ventricular area beyond the ring, there was no action potential synchronized with the atrial membrane action potential.

Fig. 17 demonstrates an example of the data in vertical and horizontal explorations performed at a septal area between the coronary sinus and pars membranacea of the interatrial septum or an area including A-V node. Horizontal exploration was made at every $2 \mathrm{~mm}$., and vertical exploration, at every $1 \mathrm{~mm}$. As an electrode approached posterior margin of this area, the activation time progressively prolonged and the membrane resting and action potentials gradually decreased.

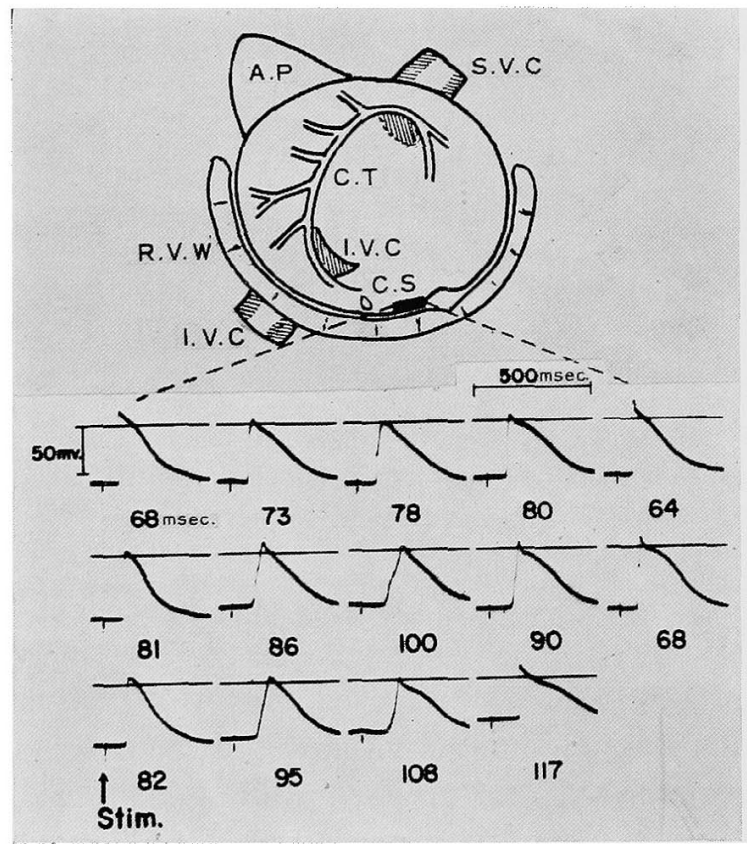

Fig. 17. Configurations and activation times of the action potentials recorded from $\mathrm{A}-\mathrm{V}$ node and its vicinity in canine heart. Vertical explorations were made at intervals of $1 \mathrm{~mm}$. and horizontal, also $1 \mathrm{~mm}$. The tracing from the $\mathrm{A}-\mathrm{V}$ node shows a diastolic slow depolarization. Numerals inserted express activation times in msec.

A.P.: Right auricular appendage.

C.T.: Crista terminalis.

C.S.: Coronary sinus orifice.

S.T.C.: Superior vena cava.

I.V.C.: Inferior vena cava.

R.V.W.: Right ventricular free wall. 
As an electrode approached the A-V ring in vertical exploration, the activation time progressively prolonged. In the vicinity of the ring, there was a diastolic slow depolarization preceding the depolarization upstroke and the onset of the activation was very late. In this case, the delay in onset of activation was about $20 \mathrm{msec}$. as compared with that of the point having no diastolic prepotential. The activation wave in this area secmd to be conducted through 2 routes, right and septal branches of crista terminalis.

\section{Drscussion}

\section{1) S-A node and its vicinity}

Many authors have hitologically examined the location of S-A node. According to Keith and Flack, ${ }^{1)}$ S-A node lies at the junction of the free border of the appendix with the mouth of the superior vena cava, and extends downwards along the sulcus terminalis for a distance of about $2 \mathrm{~cm}$. in man. This observation was also confirmed by $\mathrm{Koch}^{6)}$ and others. According to Osawa, ${ }^{22)}$ head of S-A node lie on the anterior part of the base of superior vena cava and its body and tail lies on anterior part of the right atrium close to sulcus terminalis. The location of S-A node in their reports is nearly the same.

Electrophysiologically, however, there still remains a question whether the musculature of this part really works as the pacemaker of the cardiac rate.

In a field of electrophysiology, it was found that the membrane action potential from the pacemaker region was characterized by existence of slow diastolic prepotential and by less steep slope of the depolarization upstroke of the transmembrane potential. ${ }^{14), 23) \sim 25)}$ This pattern of the transmembrane potential has usually been called as pacemaker potential pattern and has been supposed to be characteristic to the musculature having automaticity. West, ${ }^{24)}$ working simultaneously with 2 microelectrodes, found that the pacemaker pattern of membrane action potential was obtained from flat band of tissue lying between caval orifices of superior vena cava and inferior vena cava. The cell group found in this region may, therefore, be supposed to belong to the muscle fibers of S-A node having automaticity.

In the present experiment, these cell groups were located in a area between the superior and inferior caval orifices and included a part of the right branch of the crista terminalis. This area mainly occupied the right anterior area of the basic wall of the superior vena cava and extended in a lozenge shape with a side length of $4 \mathrm{~mm}$. Among these cell groups, the cell group showing Type A membrane action potential was found in a slender area near the crista terminalis ( 1.0 to $1.5 \mathrm{~mm}$. from crista terminalis) lying down along it. This area extended into crista terminalis at its right end. The true pacemaker, the cell 
showing earliest onset of activation of all, was located in this slender area showing Type A membrane action potential.

According to Toyoshima et al., ${ }^{26)}$ the firing rate of the musculature having automaticity is different depending on the temperature of the tissue. The higher the temperature, the greater is the frequency, and the musculature having highest firing rate controls the rate of the total tissue of the musculature. It is also known by West ${ }^{27}$ that the pacemaker shifts to another place in the S-A nodal tissue by local application of acetylcholine or epinephrine. The true pacemaker, therefore, would not necessarily be fixed at a certain cell of S-A node in the heart under the control of vegetative nervous system.

According to Matsuda and Hoshi, ${ }^{25)}$ the depolarization rate of the diastolic prepotential of a cell is proportional to the firing rate of the cell. It is also found by them that the depolarization rate of the diastolic prepotential is reversely proportional to the amplitude of the membrane resting potential. The smaller the amplitude of the membrane resting potential, the greater is the depolarization rate. The cells having Type A membrane action potential, therefore, are supposed to have a greatest possibility of being the true pacemaker. The cell having the greatest depolarization rate of the diastolic prepotential might produce the membrane action potential as the true pacemaker and control the cardiac rate. As to the cells having Type $\mathbf{B}$ membrane action potential, it would be very probable to suppose that it would not play any important role as the true pacemaker. This cell group, however, may also have a change to be the true pacemaker, if it gains the property specific to the cells having Type A action potential for some unknown reason.

The activation wave evoked at the true pacemaker is conducted more or less radially in direction. The conduction rate was, however, different depending on the direction. As shown in Fig. 5, the conduction rate was greatest in the direction toward the crista terminalis along the type $\mathrm{A}$ area. This route along the Type A zone may, therefore, be supposed to be a preferential conduction route of the sinus activation to crista terminalis.

2) Propagation of the activation in the right atrial musculature

According to Lewis, ${ }^{10}$ the activation originated in $\mathrm{S}-\mathrm{A}$ node propagates more or less radially in direction and constant in velocity. The same observation was also made by Peuch et al. ${ }^{11)} \quad$ Van de Kooi and his associates ${ }^{28}$ reported that the sinus excitation was transmitted relatively rapidly in velocity along the thick muscle bundle such as crista terminalis and $\mathrm{mm}$. pectinati and so on. In the present experiment, it was confirmed that the activation was transmitted more or less radially in direction but not in the same speed. The conduction rate was different depending on the direction. Even the rate highest in the value, however, was far smaller than that of Purkinje fiber. ${ }^{29)}$ 
The difference between highest and lowest value was rather small and the highest rate was always found along the ridge of crista terminalis. As the activation wave proceeds passing through crista terminalis, $\mathrm{mm}$. pectinati, and the atrial roof musculature, the conduction rate became progressively decreased and the rate was smallest in the atrial roof musculature.

The present data about the onset of the activation in the distal area after cutting the right and/or septal branch may give an important information about propagation of the atrial activation. The evidence that the onset of the activation in the wide area of the atrial musculature distal to the cut point not only the distal branch of the crista terminalis, but also mm. pectinati branching from the distal part of the crista terminalis displayed remarkable delay, appears to oppose the opinion that the sinus activation is transmitted almost radially in direction without any preferential route of conduction. This evidence appears to show that the sinus activation is transmitted quickestly through the both branches of crista terminalis and the activation coming along through crista terminalis is farther conducted into $\mathrm{mm}$. pectinati which are branching off from crista terminalis.

The observation about the atrial delayed conduction produced by the osmic acid administration appears to confirm the fact that the activation wave from the S-A node to the A-V node is transmitted rapidly through the both branches of the crista terminalis. There is no observation that can support the complete intra-atrial block, as reported by Tamai, ${ }^{21)}$ after the osmic acid injection. In this paper, the reason why there was no occurrence of the complete intra-atrial block was obscure.

The finding that the delay in onset of activation was more remarkable in the distal area near the cut point than the mush more distal area as compared with their control, appears to suggest that the activation strayed into the proximal end of the distal part of crista terminalis may farther be conducted with higher rate than that through the other part of the atrial musculature of that area. It means the distal part of crista terminalis still shows an accelerated conduction once a stimulus strayed into this part of crista terminalis. It was very interesting that the conduction rate of the atrial musculature was related to the thickness of the musculature. Crista terminalis as well as Bachmann's bundle is the thickest of all the atrial musculature. Mm. pectinati are less thick than crista terminalis and the atrial musculature is the thinnest. As the thickness of the musculature became decreased, the conduction rate became progressively decreased. The thickner the musculature, the higher was the conduction rate.

Recently James ${ }^{30}$ ) verified, performing a serial examination of the human tissue, that a Purkinje tissue was running through the crista terminalis. The 
rapid conduction through the crista terminalis was attributed to this tissue.

According to Paes de Carvalho et al., ${ }^{14)}$ there is a whitish bundle of tissue called sino-atrial ring bundle, separating the great veins from auricular muscle, and this bundle describes an almost complete loop around the 2 venae cavae and the coronary sinus. According to them, the sinus activation is transmitted toward the A-V nodal region most rapidly through the musculature of this ring bundle. The authors, however, could find neither sinoatrial ring bundle nor stretched zone characterized by the membrane action potential of the ring bundle pattern. The action potential of the S-A ring bundle pattern was recorded only from a marginal zone of the S-A nodal region in the present experiment. Rothberger and Scherf," Condrelli, ${ }^{8)}$ Takayasu, ${ }^{\text {") }}$ and other authors observed a few muscle bundles running from S-A node toward A-V node through the atrium. These bundles were supposed to be a kind of conduction system of the impulse from S-A node to A-V node. According to some of these workers, the conduction rate through these specific bundles is much higher than the ordinary atrial musculature.

Independently from the electrophysiological studies, many histological studies have been carried out to approach the question whether there is a specific conduction system in the atria or not. For example, by Torel, ${ }^{311}$ Monckeberg, ${ }^{32)}$ Osawa, ${ }^{33)}$ Tamura, ${ }^{34)}$ Nomura, ${ }^{35)}$ and Glomset. ${ }^{36)}$ However, their results have not yet been necessarily unified. As far as the present experiment pursued, there were 2 routes through which the sinus activation was transmitted quicker than any other route toward the $A-V$ nodal region. As it is well known, however, one of the most important role of A-V node is to delay the impulse transmission from atrium to ventricle. If it is so, the accelerated conduction of the activation would not be necessary to activate A-V node. An important thing for atrial musculature would be a sure transmission of the impulse toward $\mathrm{A}-\mathrm{V}$ node.

There is another question whether $\mathrm{A}-\mathrm{V}$ node may be activated by the impulse which arrives first at the A-V nodal region despite any route it comes along or by the impulse which comes along through some specific routes. This question is also not settled. However, provided that A-V node is activated by the impulse which arrives first at the nodal region, despite any route the impulse comes along through, then, the 2 routes, the both branches of crista terminalis, would be important routes to transmit the sinus activation to A-V node. In the present experiment, an effort was made to make clear the question, which branch is more pronounced in impulse conduction to A-V node. In some cases, the septal branch transmitted the activation to A-V nodal region quicker than the right branch and in some cases it was just opposite. By giving some injuries to a branch, the activation times in the vicinity 
of A-V node displayed some minor delay whereas they showed marked delay by additional injury to the other branch. It was, therefore, very difficult to decide which branch is more effective to sinus impulse transmission to $\mathrm{A}-\mathrm{V}$ node. It was also suspected that the location of the true pacemaker would also give an great influences to the arrival time of the activation wave at the A-V nodal region.

Independently from the stimulus conduction from S-A node to A-V node, the accelerated conduction through crista terminalis was supposed to be quite reasonable for efficient atrial work to drive out the blood into the ventricle. The accelerated conduction through crista terminalis may, therefore, be primarily for the efficient driving out of the atrial blood.

At the present time, little is known with the genesis of the plateau of the transmembrane potential. Plateau is usually known as specific to cardiac muscle fiber. It is very interesting that the plateau became more pronounced as the conduction rate of the musculature increased, or as the thickness of the musculature increased and became less pronounced as the conduction rate of the musculature decreased or, as the thickness of the musculature decreased.

3) Transmission of the activation in the vicinities of $\mathrm{A}-\mathrm{V}$ ring and $\mathrm{A}-\mathrm{V}$ node

According to Paes de Carvalho et al., ${ }^{14)}$ the activation time of the atrial musculature in the vicinity of the atrioventricular ring was about $70 \mathrm{msec}$. in rabbit heart. In the present experiment, it was different from animal to animal and was in a range from 70 to $100 \mathrm{msec}$. It was, however, almost constant along the whole length of the ring as far as the exploration was performed on the same case.

As the exploring electrode approached the ring, the upstroke of the membrane action potential became progressively less steep and the onset of the action potential became progressively delayed. The amplitude of the membrane action potential became also decreased as the A-V ring is approached. The delay in onset of the activation was very pronounced compared with that in periphery of crista terminalis and $\mathrm{mm}$. pectinati. Thus, there occurred abrupt and marked slowing of the activation transmission in the vicinity of the A-V ring. These changes in the stecpness of the dcpolarization upstroke and in the conduction rate in this area have been also reported by Paes de Cavalho et al. ${ }^{14}$ )

Beyond the A-V ring, there was no membrane action potential synchronized with atrial activation. This means that the atrial activation was not transmitted directly to the ventricular musculature. For this blockade of the activation, the change in the steepness of the depolarization upstroke and in the amplitude of the membrane action potential mentioned above appears to 
play an important role. As it is well known, the slower the potential change and the lower the potential, the less effective is the stimulus current. These 2 factors would additionally work and may decrease the effect of the transmembrane potential as the cause of stimulus current. This may be one of the reason why abrupt and marked delay of activation time occurs in the vicinity of the $\mathrm{A}-\mathrm{V}$ ring and blockade of the stimulus conduction occurs between the atrial and ventricular musculatures. Of course, the authors are not opposed to the opinion that the connective tissue of $\mathrm{A}-\mathrm{V}$ ring may play an important role for the blockade of the stimulus transmission from atrial to ventricular musculature.

The diastolic slow depolarization found in an atrial area near the A-V ring was rather interesting (Fig. 15). There was no significant difference in the time of the onset of activation between this area and the adjacent area. The depolarization upstroke, however, was less steep in the former area than the latter. An area displaying a diastolic slow prepotential has been also found by Paes de Carvalho ${ }^{14}$ in an area in the vicinity of the A-V ring excepting the A-V nodal region. The reason and the question whether this area has some specialized function or not are not yet sure. According to several literatures, ${ }^{32), 37,38)}$ however, $\mathrm{A}-\mathrm{V}$ ring has a close relationship with $\mathrm{A}-\mathrm{V}$ node in its ontogenesis. It is also well known that the musculature of $\mathrm{A}-\mathrm{V}$ node has specific structure and displays a diastolic slow depolarization and less steeped slope of the depolarization upstroke of membrane action potential. From these reasons, it was suspected that some unknown relationship may exist between the above mentioned area and $A-V$ node.

According to Hoffman et al., ${ }^{39)}$ the pattern of the membrane action potential recorded from $\mathrm{A}-\mathrm{V}$ node of the rabbit heart was characterized by a decreased amplitude of the membrane resting potential and by the existence of diastolic slow depolarization, the membrane action potential tended to display notches preceding the sharp depolarization upstroke, and the conduction velocity was in the range of 0.02 to $0.05 \mathrm{M}$. $/ \mathrm{sec}$. and marked delay occurred in this region.

The membrane action potentials shown in Fig. 17 are the records obtained from this region. The records characterized by a diastolic slow depolarization, a less steep depolarization upstroke, small amplitude of membrane resting and action potentials, and an embryonic overshoot looked like very close to those reported by Hoffman et al. ${ }^{39}$ ) Therefore, they were supposed to be the transmembrane potential of the A-V nodal muscle fibers. Compared with the membrane action potentials with no diastolic slow prepotential recorded from the adjacent points, there was a marked delay in onset of the activation. The amount of the delay was 20 msec. or so and it apparently showed that 
there occurred the marked delay in conduction at this region. There are many reports as to the region where the apparent delay occurs in the atrioventricular conduction. According to Scher et al. ${ }^{40)}$ and Pruitt and Essex, ${ }^{41)}$ the most marked delay occurs in the A-V node. Hoffman and collaborators ${ }^{39)}$ also reported that the delay occurred in the A-V nodal region. The data in Fig. 17 also suggest that the delay occurs in the A-V nodal region. Since there is no simultaneous record from the His' bundle in the present data, it was not able to give farther minute discussion about where the most marked delay would occur. However, the delay in atrioventricular conduction was evidenced to occur in the $A-V$ nodal region.

\section{Summary}

(1) The origination and transmission of stimulus in right atrium of the canine or rabbit heart were studied by means of intracellular microelectrode method.

(2) The area showing pacemaker potential pattern was localized in a area anterolaterally to the basal part of superior vena cava. The length was about $4.0 \mathrm{~mm}$ and the breadth was also about $4.0 \mathrm{~mm}$. The true pacemaker potential pattern was obtained from slender zone within this area.

(3) The spread of activation in this area was more or less radially in direction and almost constant in velocity except one direction along the zone toward crista terminalis showing true pacemaker potential. In this direction, the conduction rate was rather high and it was about $0.08 \mathrm{M} . / \mathrm{sec}$.

(4) After reaching crista terminalis, the activation was conducted with more accelerated velocity toward postero-inferior rand of the coronary sinus orifice and atrial septum through the right and septal branches of crista terminalis respectively. The conduction rate was about $1.5 \mathrm{M}$. $/ \mathrm{sec}$. which was the highest in the atrial musculature.

(5) In the atrial free wall, the activation coming along through the crista terminalis was transmitted to $\mathrm{mm}$. pectinati for farther conduction toward the $\mathrm{A}-\mathrm{V}$ ring. The atrial roof musculature was activated by stimulus coming through a nearby $\mathrm{m}$. pectinatus. The conduction rate through $\mathrm{m}$. pectinatus was greater than that through atrial roof but was less than that through crista terminalis.

(6) By cutting the crista terminalis or injecting osmic acid solution into this musculature, the stimulus conduction to distal portions of crista terminalis was markedly delayed. It was supposed that both branches of the crista terminalis played the most important role in stimulus conduction in the right atrium.

(7) It was supposed that the musculature in the vicinity of the A-V 
node was activated by the stimulus coming along through 2 routes, one through the right branch and the other through the septal branch of the crista terminalis. At an area near the boundary of septal musculature and the A-V node, the conduction rate of activation wave showed marked decrease. A-V node was verified by its typical pattern of the membrane action potential.

(8) The conduction rate of the activation wave in the area close to $\mathrm{A}-\mathrm{V}$ ring became progressively decreased as the ring was approached and the activation was not transmitted beyond the ring. With this progressive decrease in the conduction rate, the membrane action potential also gradually decreased in the steepness of the sharp depolarization upstroke. It was speculated that the changes in membrane action potential were an important cause for the constant blockade of stimulus conduction between atrial and ventricular musculature.

\section{ACKNOWLEDGMENT}

The authors wish to thank Prof. $\mathrm{H}$. Toyoshima for his variable instructions. study.

The authors also are grateful to Prof. S. Hibino for his kind guidance in this

\section{REFERENCES}

1. Keith, A. and Flack, M.: J. Anat. Physiol. 41 : 172, 1907.

2. Tawara, S.: Das Reizleitungssystem des Säugetierherzens. Jena, G. Fischer, 1906.

3. Wybauw, M. R.: Arch. Internat. de Physiol. 10: 78, 1910.

4. Lewis, T., Meakins, J., and White, P. D.: Phil. Trans. Roy. Soc. B. $205:$ 375, 1914.

5. Eyster, J. A. E. and Meek, W. J. : Arch. Int. Med. 18: 775, 1916.

6. Koch, W.: Med. Klin. $328: 447,1911$.

7. Rothberger, C. J. and Scherf. D.: Zeitschr. ges. exp. Med. 53: 792, 1926.

8. Condrelli, L.: Zeitschr. ges. exp. Med. 68:593, 1929.

9. Takayasu, M., Takasaki, H., Nishi, N., Tateishi, Y., Osawa, M., Tamagaki, A., Fujiwara, H., and Ikuta, S.: Jap. Circulat. J. 18: 414, 1954 (in Japanese).

10. Lewis, T.: The Mechanism and Graphic Registration of the Heart Beat. London, Shaw and Sons, 1925.

11. Puech, P., Esclavisat, M., Sodi-Pallares, D., and Cisnoros, F.: Am. Heart J. 47: 174, 1954.

12. Ling, G. and Gerard, R. W.: J. cell. comp. Physiol. 34: 383, 1949.

13. Nastuk, W. L. and Hodgkin, A. L.: J. cell. comp. Physiol. 35 : 39, 1950.

14. Paes de Carvalho, A., Carlos de Mello, W., and Hoffman, B. F.: Am. J. Physiol. 196: 483, 1959.

15. Miyauchi, A.: Jap. Heart J. 3: 357, 1962.

16. Miyauchi, A.: Jap. Heart J. $3: 476,1962$.

17. Horiba, M. : Jap. Heart J. 4: 333, 1963.

18. Horiba, M. : Jap. Heart J. (in press)

19. Horibe, H.: Jap. Circulat. J. 25: 583, 1961.

20. Toyoshima, H., Yamada, K., Horiba, M., Miyauchi, A., Sakaida, Y., Horibe, H., Nonogawa, A., Oishi, H., Ishikawa, K., Muraki, H., and Toyama, J.: Ann. Rept. Research Inst. 
Environment. Med., Nagoya Univ. 11 : 39, 1963.

21. Tamai, H.: Mie Med. J. 12: 171, 1962.

22. Osawa, M.: Jap. Circulat. J. 23: 1014, 1959.

23. Brady, A. J. and Hecht, H. H. : Am. J. Med. 17: 110, 1954.

24. West, T. C. : J. Pharm. Exp. Therap. $115: 283,1955$.

25. Matsuda, K. and Hoshi, T.: The automaticity of the heart muscle ccll. Bunkodo, Tokyo, 1959 (in Japanese).

26. Toyoshima, H. and Kato, H.: Ann. Rept. Research Inst. Environment. Med., Nagoya Univ. 1 : 67, 1948 (in Japanese).

27. West, T. C.: J. Pharm. Exp. Therap. 117: 245, 1956.

28. van de Kooi, N. W., Durrer, D., van Dam. R., and van der Tweel, L. H. : Am. Heart J. 51 : $684,1956$.

29. Draper, M. H. and Weidmann, S. J.: J. Physiol. 115: 74, 1951.

30. James, T. N。: Am. Heart J. $66: 498,1963$.

31. Thorel, G.: Verhandl. d. Deutsch. Path. Gesell. 14: 71, 1910.

32. Mönckeberg, J. G. : Ergeb. d. allgem. Pathol. u. pathol. Anat. 19: 328, 1921.

33. Osawa, M.: Jap. Circulat. J. $23: 1014,1959$ (in Japanese).

34. Tamura, O.: Tokyo Iji-Shinshi, 2812: 215, 1933. and $2879: 1231,1934$ (in Japanese).

35. Nomura, S.: Cyst. and neurol. Study $10: 211,1952$.

36. Glomset, D. J. and Glomset. A. T. A. : Am. Heart J. $20: 389,1940$.

37. Aschoff, L.: Zentralbl. allgem. Pathol. $21: 433,1910$.

38. Koch, W.: Pflügers Arch. ges. Physiol. 151 : $229,1913$.

39. Hoffman, B. F., Paes de Carvalho, A., Carlos de Mello, W., and Cranefield, P. F. : Circulat. Res. 7: 54, 1959.

41. Pruitt, R. D. and Essex, H. E. : Circulat. Res. 8 : 149, 1960. 